artelogie

\section{Artelogie}

Recherche sur les arts, le patrimoine et la littérature de l'Amérique latine

$7 \mid 2015$

Photographie contemporaine en Amérique latine

\title{
A revista mexicana Frente a Frente: ambiguidades e tensões entre fotomontagens vanguardistas e gravuras
}

\section{Carlos Alberto Sampaio Barbosa}

\section{(2) OpenEdition \\ 1 Journals}

\section{Edição electrónica}

URL: https://journals.openedition.org/artelogie/1108

DOI: 10.4000/artelogie.1108

ISSN: 2115-6395

\section{Editora}

Association ESCAL

\section{Refêrencia eletrónica}

Carlos Alberto Sampaio Barbosa, «A revista mexicana Frente a Frente: ambiguidades e tensões entre fotomontagens vanguardistas e gravuras», Artelogie [Online], 7 | 2015, posto online no dia 15 abril 2015, consultado o 11 abril 2022. URL: http://journals.openedition.org/artelogie/1108 ; DOI: https:// doi.org/10.4000/artelogie.1108

Este documento foi criado de forma automática no dia 11 abril 2022.

Association ESCAL 


\title{
A revista mexicana Frente a Frente: ambiguidades e tensões entre fotomontagens vanguardistas e gravuras
}

\author{
Carlos Alberto Sampaio Barbosa
}

1 A revista Frente a Frente foi uma publicação da Liga de Escritores y Artistas Revolucionários (LEAR) ${ }^{1}$. Essa organização surgiu em 1934 na esteira de movimentos anti-fascistas e de defesa da cultura na Europa como a Associação Internacional de Escritores e Artistas Revolucionários (AIEAR), criada na cidade de Cracovia (Polônia) durante o Congresso Internacional de Cultura Proletária (1930) e que em seguida contou com a adesão dos John Reed Clubs (JRC) dos Estados Unidos e a Associação de Escritores e Artistas Revolucionários (AEAR) da França. A liga mexicana esperava tornar-se a "seção mexicana" dessas organizações. Seus membros fundadores foram o escritor Juan de la Cabada e os artistas plásticos David Alfaro Siqueiros, Leopoldo Méndez, Pablo O'Higgins, e posteriormente outros artistas e intelectuais se juntaram ao grupo inicial, como Luis Arenal, Germán List Arzubid, José Mancisidor e Julio de la Fuente. ${ }^{2}$

2 A liga estruturou-se em seções de pintura, literatura, música, artes cênicas, educação e posteriormente serão criadas outras como a científica, arquitetura, fotografia e cinema. Em 1934 o grupo já possuía mais de 30 filiados e se propunha a organizar diversas atividades como cursos de idiomas, conferências, exibições de cinema e uma escola para trabalhadores. Sua inspiração era a Université Ouvrière de Paris e a Maison de la Culture mantida pelos comunistas franceses. Possivelmente a liga tenha tomado conhecimento da sua homônima francesa e procurado seguir a máxima leninista manifestada no congresso de 1930: "A arte é uma arma da luta de classes, para ser usada sob o guia do partido comunista." (REYES PALMA, 1994: 7). A revista surge como órgão de imprensa da liga, fazia parte de uma ação mais ampla de publicação e divulgação de suas ideias e projetos. Para tanto a liga publicava também folhetos, folhas soltas e cartazes com gravuras de teor político. Outro exemplo de atividades da LEAR era a Oficina Escola de 
Artes Plásticas organizada por Siqueiros em 1935; essa possuía como objetivos centrais além de formar quadros de operário-artistas capacitá-los nas tarefas de agitação política.

3 A liga demorou um ano para lançar sua publicação própria, e o título "Frente a Frente" estava vinculado ao período político que o movimento comunista vivia de confrontação de classe característico da VI Internacional o que denota um vínculo com a ideia de classe contra classe ${ }^{3}$. Entretanto, como pretendemos demonstrar, sua trajetória não foi isenta de tensões, ambiguidades e contradições tanto política como estética, principalmente entre as propostas estéticas de utilização da cultura operária (proletkult), do realismo socialista ${ }^{4} \mathrm{e}$ das vanguardas.

4 O número inaugural da revista veio a público no final da presidência do General Abelardo Rodríguez (1932-1934) no México e no transcurso da campanha do candidato Lázaro Cárdenas. O segundo número sai em janeiro de 1935 já sob a presidência de Cárdenas (1934-1940). Sua política editorial, declarações e ilustrações expressavam o engajamento de artistas-intelectuais às questões sociais contemporâneas (Azuela, 1993: 82). A liga (LEAR) surgia no contexto de combate ao nazi-fascismo, ao imperialismo e defesa da cultura e embora possuísse vínculos com o Partido Comunista Mexicano constatamos que na sua trajetória atuaram artistas de várias tendências políticas da esquerda. Nesse sentido acredito que embora os comunistas fossem hegemônicos, artistas e intelectuais de outras tendências ideológicas também participaram desse movimento. Algo similar ocorria com grupos e publicações antifascistas no Cone Sul (OLIVEIRA, 2013:17).

5 Mesmo que brevemente devemos nos ater à materialidade da revista, visto que essa não é fruto do mero acaso, mas sim da interação entre condições técnicas de impressão e as escolhas feitas por seus editores o que revelam o lugar social das mesmas. A revista Frente a Frente publicou 16 números entre novembro de 1934 e janeiro de 1938. Propunha a ser mensal embora tenha sido publicada irregularmente. Durante todo o período a publicação não manteve uma periodicidade regular: em momentos foi mensal, bimensal e chega a ficar nove meses sem circular. (REYES PALMA, 1994: 9) Suas tiragens giravam em torno de 2.000 exemplares, embora chegasse a incríveis 10.000 exemplares. Ela possuía os mesmos circuitos de distribuição do jornal vinculado ao Partido Comunista Mexicano (PCM) El Machete e contava com uma rede internacional de distribuição em países como os Estados Unidos, Porto Rico, Cuba, Panamá e Espanha. Em termos de imagens suas preferências eram por reproduções de murais, arte pública, desenhos, fotografias, fotomontagens, gravuras, litografias.

6 Podemos falar que a revista teve três fases pontuadas pela troca de direção mas que se expressam também na dimensão da publicação. Uma primeira fase compreende os três primeiros números entre novembro de 1934 e maio de 1935, em que a revista possuía a dimensão de 33,5 x $23 \mathrm{~cm}^{5}$. A segunda, entre 1936 e 1937 (6 números) sob a direção de Fernando Gamboa ${ }^{6}$ a revista aumenta de tamanho passando para $42 \times 34 \mathrm{~cm}$, próximo de um formato tablóide e com nova numeração ; e uma terceira fase entre 1937 e 1938 (7 números) já com Raimundo Mancisidor como editor; nessa fase os dois últimos números retornam ao tamanho inicial menor.

7 A primeira fase era efetivamente de oposição ao governo mexicano, chamado em textos internos de 'social-fascista' ${ }^{7} \mathrm{e}$ mais vinculada às concepções de cultura proletária e do realismo socialista. O secretário geral do Partido Comunista Mexicano (PCM) Hernán Laborde dispunha de espaço nas páginas da publicação e seu comitê editor, embora 
tenha sofrido mudanças, mantém um núcleo que era composto pelos próprios fundadores da liga Juan de la Cabada, Leopoldo Méndez, Luis Arenal e David Alfaro Siqueiros. Participava também um personagem que ficou anônimo e que assinava como Rab-Kor, pseudônimo de "rabochiikorrespondient", ou seja, correspondente operário e que enviava reportagens desde Moscou. O muralista Siqueiros só permaneceu nos expedientes da revista nos primeiros dois números.

8 A circulação da revista contava com comissões que distribuíam a publicação a dirigentes sindicais e ao movimento operário além de promover a venda direta nos sindicatos. A partir do terceiro número começa a ser distribuída em diversos pontos dos Estados Unidos. Sem dúvida buscavam atingir os migrantes mexicanos do campo e da cidade em solo norte-americano e é claro também aos intelectuais estadunidenses sensibilizados à causa da associação e próximos aos ideais do Partido Comunista estadunidense. Cabe destacar que sua distribuição coincidia com as do jornal do partido El Machete. No México a publicação custava dez centavos e um peso pela subscrição anual. Nos Estados Unidos era vendida a cinco centavos de dólar cada número e a assinatura custava cinquenta centavos.

9 A revista contava com representantes em Chicago, Los Angeles, São Francisco e Nova York. Nesta última cidade era vendida em restaurantes e na livraria Lago de Enrique Martínez. Segundo Reyes Palma (1994: 9) 500 exemplares do periódico chegavam a ser vendidos em Nova York. Nessa cidade a LEAR mantinha contatos com grupos como a Mutualista Obrera Mexicana, o John Reed Club e a revista do Partido Comunista norteamericana New Masses. Além de contatos com o Club Mella ${ }^{8}$ vinculados a exilados cubanos. Existem informações que exemplares foram enviados para a União Internacional de Escritores Revolucionários da União Soviética e a AEAR francesa. Um dos distribuidores mais ativos foi Ramón Pi Castella conhecido como "El Internacional Rojo", que por seus próprios recursos e desde Nova York enviava a revista para Porto Rico, Cuba, Panamá, Espanha e o Sul dos Estados Unidos. Embora não se possa mensurar a constância e regularidade desta distribuição é um dado importante que denota uma rede de simpatizantes e distribuidores da publicação quase que em todo o território norte-americano e diversos países da América Latina e Europa.

Em meados de 1935 a publicação enfrenta uma crise editorial que reflete as transformações por que passava a LEAR com a fusão e incorporação de outros grupos culturais e políticos e a uma readequação do campo das esquerdas que leva a um reordenamento da publicação. A revista fica nove meses sem ser publicada devido a esses fatores e questões financeiras. Volta em março de 1936 sob nova direção de Fernando Gamboa

11 Em meados de 1935 ocorre uma transformação na LEAR com a fusão e incorporação de outros grupos tais como o Noviembre, que editava a revista Ruta, seguida pela adesão do Sindicato de Escritores e Artistas Revolucionários, Federação de Escritores e Artistas Proletários (FEAP) e a Associação de Trabalhadores de Artes Plásticas. Tanto essas fusões com outras agrupações como mudanças no campo político nacional com a ruptura entre o presidente Lázaro Cárdenas e Plutarco Elias Calles, assim como a situação internacional, com a realização do VII Congresso da Internacional Comunista, no qual se redefiniu a política de seus partidários, abandonando a proposta de luta de classe contra classe para a de frente ampla ou popular, levou a um reordenamento dentro da LEAR e por conseqüência de sua publicação Frente a Frente. Essas mudanças representavam uma readequação do campo da esquerda no México na luta contra o fascismo. Após uma 
interrupção de nove meses, motivadas também por motivos financeiros e muito provavelmente para a reacomodação dos novos participantes à revista, Frente a Frente entra numa nova época e volta a ser publicada em março de 1936. Essas transformações levaram ao surgimento de novas filiais da liga em diversas regiões do território mexicano, tornando a LEAR um movimento nacional.

No número de março de 1936 a revista é relançada com nova numeração quando se inicia a segunda fase agora com a direção de Fernando Gamboa durante a qual publicou os próximos seis números. Em termos de vínculos políticos um dos principais exemplos foi a participação de Vicente Lombardo Toledano ${ }^{9}$, considerado antes como traidor da classe operária, a partir desse ponto lhe foi permitido publicar um artigo no impresso. Sob a direção de Gamboa a revista tentou manter uma periodicidade mensal. Além das alterações materiais (dimensão da revista que aumentou), a mudança de concepção também foi significativa com o novo projeto editorial e visual, atestado pela mudança nas capas com o maior uso de fotografia e fotomontagens, o que denota uma maior aproximação às propostas das vanguardas.

o projeto editorial da nova fase previa as mesmas seções que anteriormente (literatura, artes plásticas, música, teatro, cinema, educação, ciência, arquitetura e fotografia). Mas a fotografia como afirma Reyes Palma, "não só como ilustração geral, se não como base de ensaios fotográficos a página dupla." (1994: 10) Outra mudança significativa se deu na posição com respeito à vanguardas artísticas antes criticadas por um suposto artepurismo; a partir desse momento, embora de forma muito tímida, são aceitas.

Durante o ano de 1936 as páginas da revista foram espaço, de maneira oblíqua, de um debate entre os defensores de uma postura mais próxima ao realismo socialista como Juan de la Cabada e Arqueles Verla, em contraposição a um artigo muito crítico do intelectual guatemalteco e membro da liga Luis Cardoza y Aragón (1901-1992) publicado no jornal El Machete em que afirmava a mediocridade das obras ali expostas. Cabada e Verla vão defender que o papel do artista e intelectual engajado deveria ser de um "engenheiro de almas" segundo a frase atribuída a Stalin. ${ }^{10}$ Segundo esses autores essa última posição deveria ser o papel de uma cultura frentista. Esses embates de certa forma replicavam as disputas com o grupo dos Contemporâneos e dos surrealistas, assim como diferenças estéticos-políticas do grupo de filiação trotskista. Mas o que podemos perceber é que esse debate ou tensão ficaram mais explicitadas nas mudanças do projeto visual da revista em especial no contraste entre gravuras e fotomontagens. Pois estas últimas possuem um caráter de aproximação com as propostas das vanguardas. Voltaremos a esse tema no próximo item desse artigo.

Em 1937 após a realização do Congresso Nacional de Escritores e Artistas, assume a direção da revista Raimundo Mancisidor ${ }^{11}$ em substituição a Gamboa. A administração financeira fica a cargo de Ramón Arroyo e a revista se torna bimensal. Mancisidor publica sete números como editor responsável. Ainda nos meses de abril e maio há um racha na revista com a saída de Leopoldo Méndez ${ }^{12}$ responsável pelo setor plástico, talvez o mais dinâmico e rico da revista. Méndez sai e funda o Taller de Gráfica Popular (TGP). Essa ruptura se dá durante a gestão de José Mancisidor ${ }^{13}$ a frente da Liga. Nesse momento surgem críticas à liga pelo seu "sectarismo, corrupção e burocratismo". Este giro político ocorre paralelamente à mudança do PCM. (REYES PALMA, 1994: 15)

16 É neste cenário que a Liga e sua publicação entram em crise, e todavia conseguem publicar alguns números. A Liga e seu órgão de imprensa encerram sua trajetória quando tinham mais força. Quais os motivos que levaram a seu repentino fim? São 
vários os motivos que podem ser apontados e Reyes Palma (1994:15) destaca alguns : a ruptura do grupo de artistas ligados a Leopoldo Méndez que fundam o TGP ; o fato de que muitos dos principais artistas-intelectuais fundamentais do projeto estavam fora do México, principalmente na Espanha ; a hipótese de que a força política angariada era equivalente ao grau de pressão e risco ao movimento; no âmbito político o governo estava mergulhado nas reformas econômicas e políticas e não tinha interesse em manter um grupo de intelectuais radicais somada a própria perda de autonomia política do grupo com sua aproximação ao governo ; na dimensão externa a União Soviética e Stalin estavam interessados em um México pacificado em vista da aproximação da guerra, com isto não queria um grupo que pudesse causar problemas com o governo mexicano; e, por fim mas não menos importante as mudanças internas ocorrida no PCM. Em janeiro de 1938 sai à luz o último número da revista Frente a Frente.

\section{0 projeto visual de Frente a Frente}

17 A revista Frente a Frente em toda sua trajetória é marcada por tensões e contradições políticas e culturais, como já dito anteriormente. Seu projeto visual é marcado por uma tensão entre gravura e a fotografia e entre a opção por seguir a cultura proletária, realismo socialista ou as vanguardas, enfim entre tradição e ruptura. Em sua primeira fase (três números) o projeto é simples e calcado nas gravuras. Poucas fotografias são impressas.

Figura 1: Capa do primeiro números da revista Frente a Frente, nov/1934. Gravura de Leopoldo Méndez Calaveras del Mausoleo Nacional. Na legenda se lê : 'Calaveras del Mausoleo Nacional. Sugeridas por 'Llamadas proletarias' (?), atahuesos en música (?) de Chávez. Riva Palacio - Échame fuera, gendarmes, (llamando) al pelada gritón ! Diego Rivera - Bravo ! pues en paz no dejan gozar nuestro vacilón. ( $Y$ siguen las 'llamadas !...)'

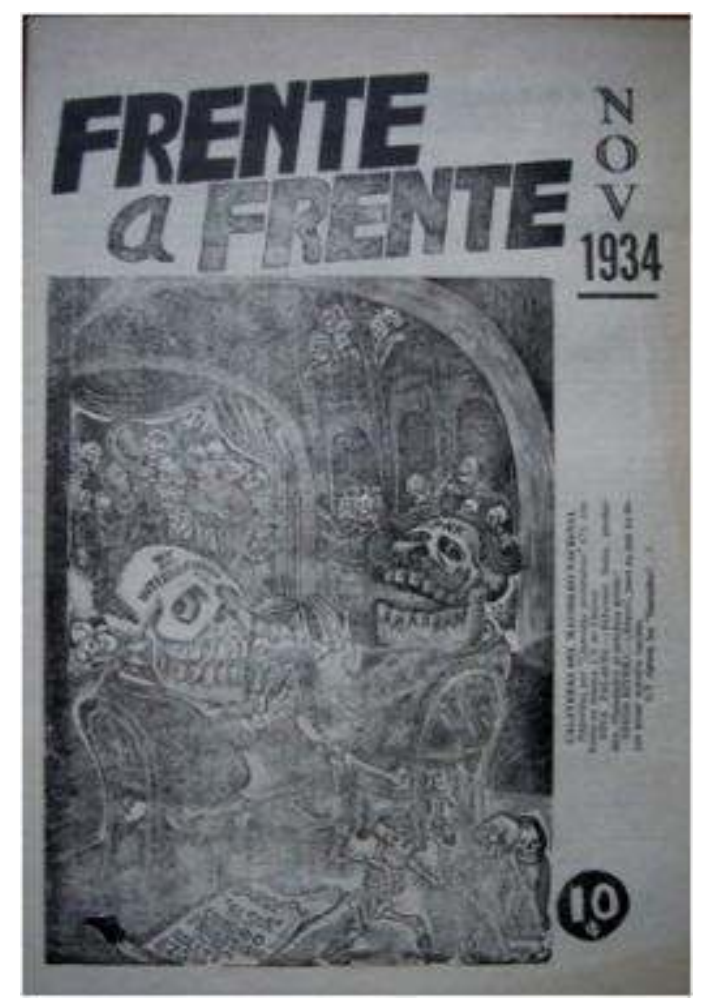


Figura 2: Capa do segundo número da revista Frente a Frente enero/1935. Gravura de Luis Arenal

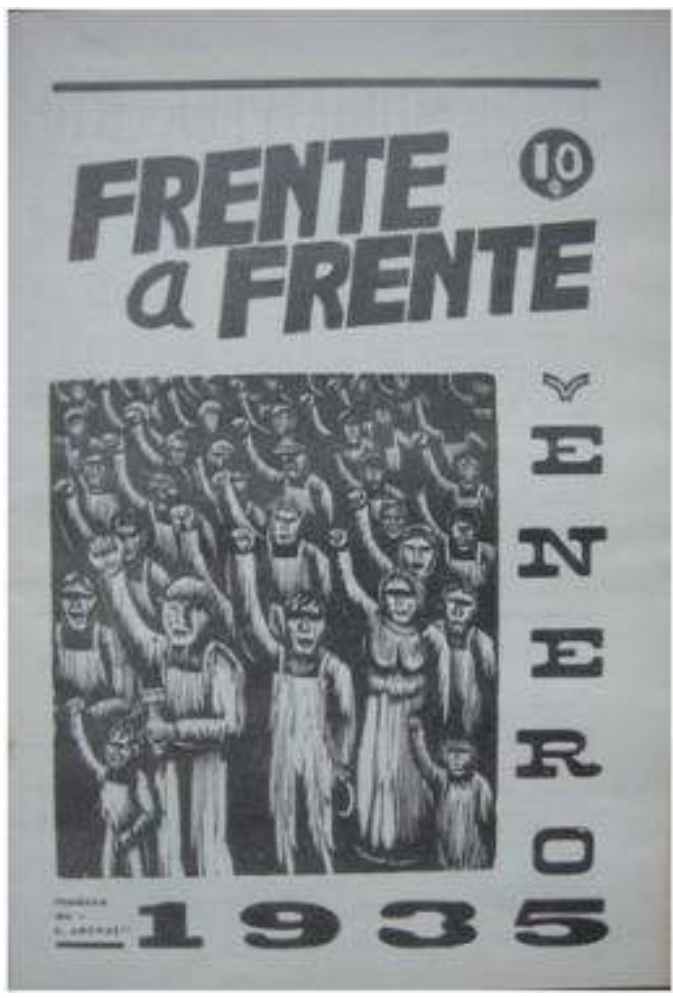

Destaque para as capas dos primeiros números. Elas são simbólicas e ficaram a cargo de Leopoldo Méndez e Luis Arenal 14. Na primeira (Figura 1) Méndez recorre às caveiras populares dos dias dos mortos eternizadas por José Guadalupe Posada com críticas a Diego Rivera que aparece como um roliço esqueleto trotskista (com a inscrição IV Internacional na testa) e ao seu lado Carlos Riva Palacio, o presidente do Partido Nacional Revolucionário (PNR), em um teatro, assistindo a apresentação da Sinfonia Proletária do maestro e compositor Carlos Chávez com bigode hitleriano. Com fina ironia Méndez une seus opositores na esfera da cultura e da política Rivera, Palacio e Chávez como símbolos de uma cultura cooptada pelo Estado. ${ }^{14}$

No segundo número (Figura 2) Luis Arenal trabalha com o gesto do punho fechado que converte-se em um símbolo de luta, clama à ação direta e representa a identidade de classe emancipada. 0 punho para o alto fala-nos de uma linguagem corporal e visual universal dos trabalhadores urbanos. Transmitem coesão e convicção do triunfo. Alguns levam a foice e o martelo símbolos tradicionais do comunismo e as mulheres levam (de acordo com o papel tradicional que lhes confere) seus filhos pelas mãos. (Hernández Pérez, 2003: 90)

Mas as gravuras internas ${ }^{15}$ são mais ricas e são marcantes as apropriações de trabalhos plásticos de Max Beckman, George Grosz e Emil Node, portanto do expressionismo alemão. Os artistas mexicanos foram muito impactados por uma exposição desses autores, organizada por Gabriel Fernández Ledesma em 1931 no Salão de Arte na cidade do México. Acreditamos que eles eram especialmente sensíveis à maneira como os alemães usavam técnicas de gravura com linhas fortes e características muito pronunciadas. Segundo Alicia Azuela 'Os [artistas] mexicanos usavam o potencial dramático da gravura para enfatizar as injustiças sociais em vez da angústia mental da psicologia humana' (1993: 87). 
Optamos por analisar as gravuras de José Chávez Morado ${ }^{16} \mathrm{com}$ duas gravuras no número de abril de 1936. Na primeira (Figura 3) uma cena de piñata representando um trabalhador que é malhado por um padre enquanto um burguês gordo, mulheres e crianças aplaudem a cena. As características do homem gordo e burguês à direita relembram as faces malévola e grotescas de Nolde e uma iconografia engajada de publicações operárias. Na outra (Figura 4) representa uma repressão de fascistas a um grupo de estudantes comunistas, trabalhadores e fazendeiros. Os agressores montados em cavalos estão com vestimentas militares e atacam os manifestantes.

Figura 3 :Gravura de José Chávez Morado Revista

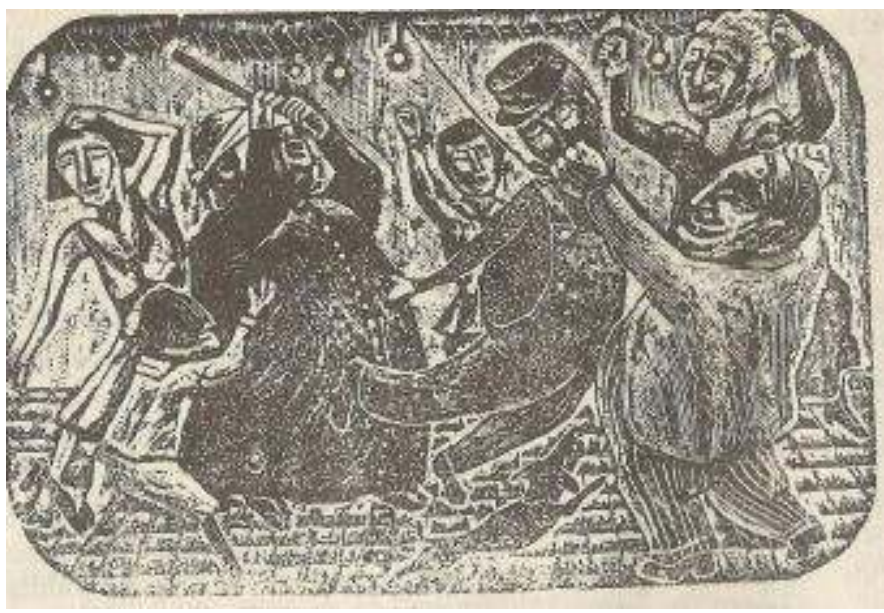

Frente a Frente n² abril, 1936, p. 18 e 22.

Figura 4 : Gravura de José Chávez Morado Revista

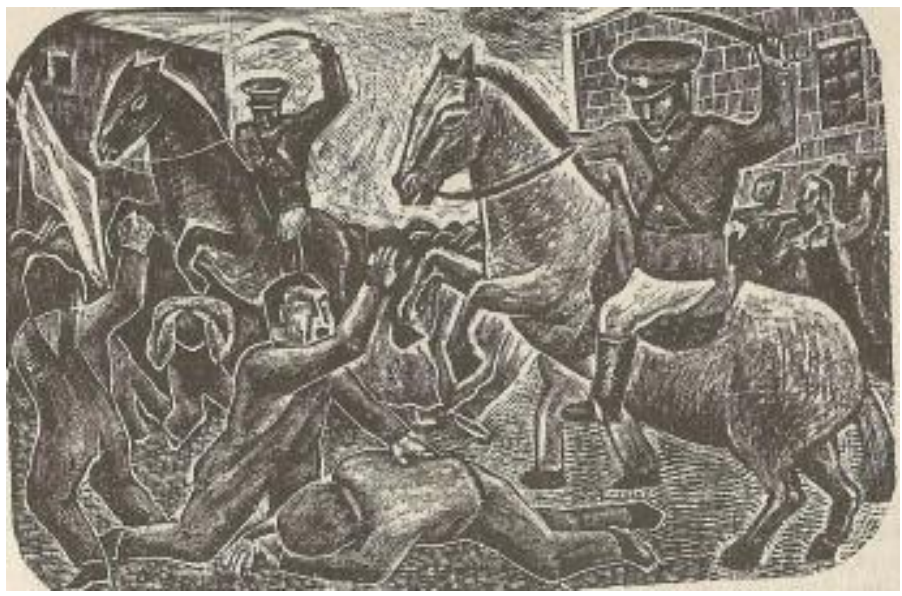

Frente a Frente n², abril, 1936, p. 18 e 22

21 A simplificação das formas, uso de linhas paralelas e claros e escuros estão ligados a representações típicas do expressionismo. A fatura de Chávez Morado assim como de Leopoldo Méndez ou Arenal combinam a qualidade primitiva dos primeiros trabalhos de Posada, como suas representações de combates, com a técnica de linhas fortes e grossas e o contraste tonal dos artistas visuais alemães contemporâneos. Essas imagens dialogam e contrastam com as fotografias e fotomontagens presentes em outros números. Em especial a presença das fotomontagens chama a atenção por ocupar um local privilegiado, como é o caso das capas, a partir da segunda fase da revista. A escolha por esta expressão plástica denota uma opção inovadora e criativa e um 
abandono das propostas do realismo socialista por outra em sintonia com as vanguardas. Essas mudanças que podem parecer contraditórias mas são resultado de um processo político e visual complexo.

Figura 5: Capa do primeiro número da segunda fase de Março de 1936

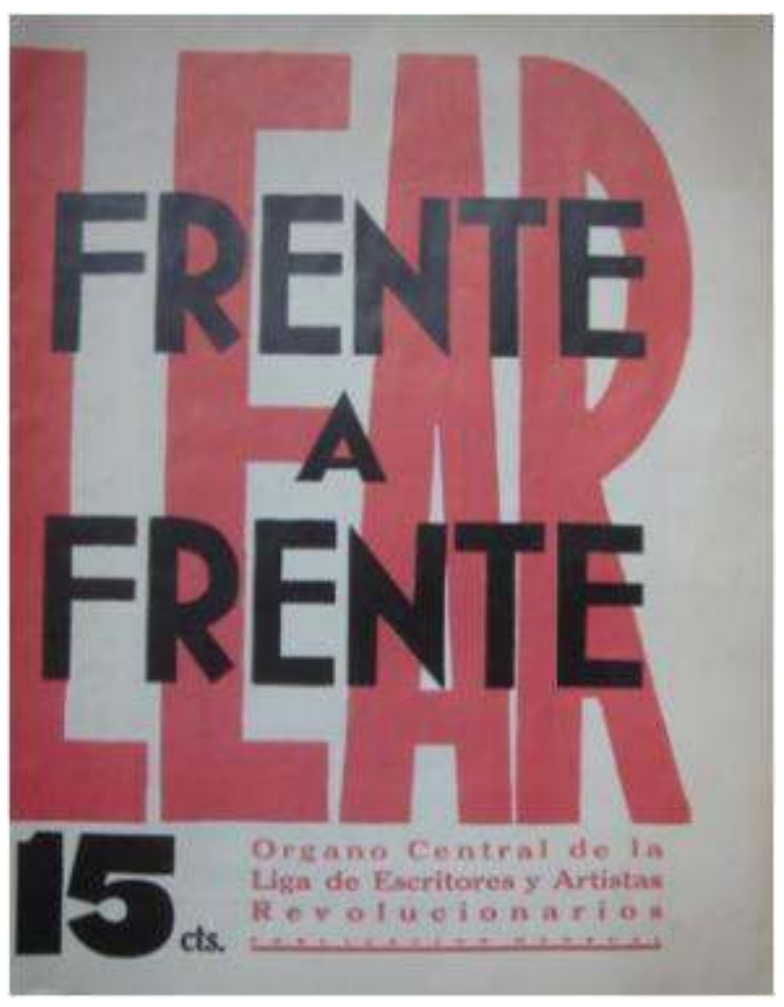

Nas capas dos dois primeiros números da segunda fase optou-se por um jogo de escalas tipográficas com o fundo com as iniciais da liga em vermelho e o nome da revista sobreposto em tamanho menor e em preto em um contraste cromático (Figura 5). Como afirma Reyes Palma 'geometria de ritmos puros, ortogonais, que muito bem poderia ser atribuído ao pintor Carlos Mérida que formava parte do comitê editorial.' (1994: 11). Essa escolha de cores remete também as capas da revista de vanguarda soviética LEF (1923) desenhadas por Ródtchenko.

Nos números seguintes o projeto editorial opta por realizar números monográficos, com temas como: Fascismo, União Soviética, Guerra Civil na Espanha e Imperialismo. Nesses números os editores optam por fotomontagens nas capas. A capa do número 3 (nova série) de maio de 1936 (Figura 6) utiliza de uma fotomontagem, como uma espécie de índice visual, para recordar a proximidade do fascismo. Essa capa simbolicamente, pois é a primeira fotomontagem a ocupar a capa, revela uma transição na revista. As fotos de Hitler, Mussolini e Calles é finalizada com a famosa fotografia de Manuel Alvarez Bravo 'Operário em greve, assassinado' (1934), imagem que condiciona a leitura das outras. Essa fotografia como nos fala Olivier Debroise torna-se:

"documento social arquetípicas del arte mexicano del periodo de Lázaro Cárdenas y puede equipararse, en el terreno de la fotografía, con las composiciones murales y los carteles impresos elaborados por la Liga de Escritores y Artistas Revolucionarios y el Taller de la Gráfica Popular, respectivamente." (2005 : 318) 
Figura 6: Capa da revista Frente a Frente, $n^{\circ}$ 3, maio de 1936

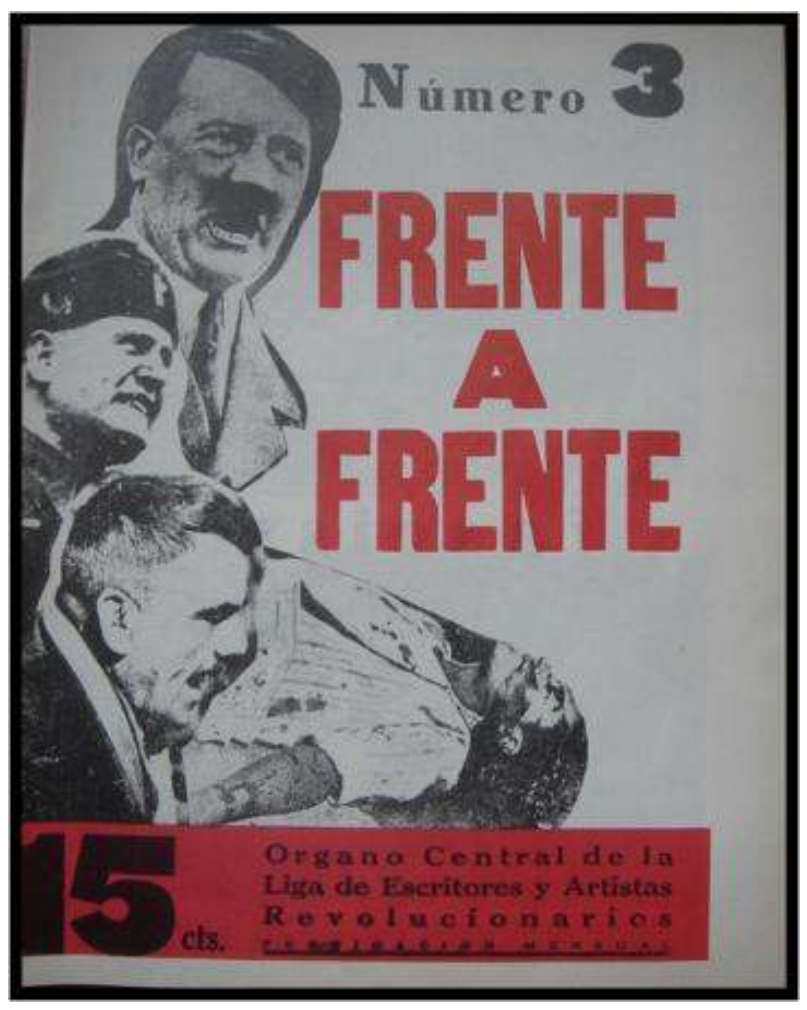

com fotomontagem sem autoria

24 A fotografia tomada em Tehuantepec em 1934 é uma das imagens de Manuel Ávarez Bravo de maior tom documental. A utilização da fotografia na capa/fotomontagem embora perca um pouco de suas qualidades 'realistas', devido à faixa vermelha com as informações da revista que cobre o sangue escorrendo da boca do operário, ainda causa um profundo impacto visual. Álvarez Bravo foi um dos principais autores de fotografias vanguardistas e sua obra considerada como a mais surrealista dos fotógrafos mexicanos ${ }^{17}$. Essa imagem arquetípica além de ser utilizada para essa fotomontagem também foi publicada na edição de março de 1936 com a seguinte legenda 'camponês assassinado por guardas brancos na luta pela terra' (Frente a Frente, $\mathrm{n}^{\circ}$ 1, 1936: 13) e será apropriada outras vezes como dez anos depois na capa da edição de janeiro da revista progressista $1946{ }^{18}$. Voltando a nossa fotografia, como afirma Laura González Flores essa imagem foi um exemplo do processo de 'artistificação' (GONZÁLEZ FLORES, 2004: 235-240) da fotografia documental e suas seguidas apropriações e resignificações por outros meios de difusão que atestariam o vigor da imagem. ${ }^{19}$

Mas talvez o número mais sugestivo da Frente a Frente seja o número 4 referente ao mês de julho de 1936 cujo tema era a União Soviética (Figura 7). Com um cartaz soviético de Gustavs Klutsis ${ }^{20}$ no canto superior direito. No canto inferior esquerdo uma fotomontagem de Josep Renau feito a partir de outra fotomontagem de John Heartfield. 
Figura 7: Capa da revista Frente a Frene, n 4, julho de 1936

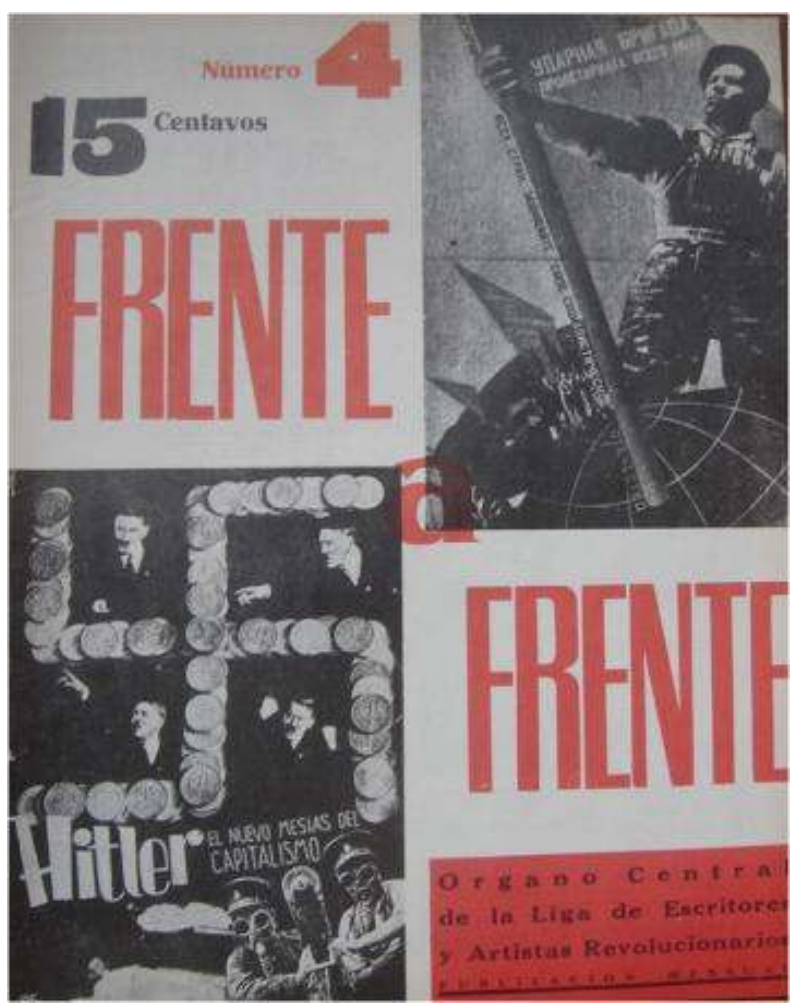

Vejamos com um pouco mais de cuidado o percurso e as apropriações dessas fotomontagens que formam essa capa. Na parte superior um cartaz de propaganda política de Klutsis denominado 'Brigada de Choque do Operariado Mundial' de 1931. O texto no cartaz diz 'trabalhadores do mundo, protejam a pátria socialista' bem no espírito do embates da década de 1930 em contrapor o socialismo contra o fascismo. Klutsis um dos pioneiros das fotomontagens políticas - se não seu inventor - foi um dos membros da vanguarda construtivista russa dos anos 1920 e 1930 ao lado de nomes como Aleksandr Ródtchenko. Nesse cartaz o fotomontador mantém a utilização de recursos visuais recorrentes das vanguardas construtivas russas como as diagonais, representada pelo mastro da bandeira segurado pelo operário, assim como o circulo do globo situado na parte inferior da imagem. Como em trabalhos anteriores surge o operário como o herói positivo. Como afirma Annateresa Fabris sobre o autor desse cartaz

'Nesse contexto, os cartazes realizados por Klutsis na década de 1930 podem ser vistos como peças de propaganda muito eficazes : ocultam as tensões que agitavam a União Soviética por trás da imagem de uma sociedade unida num esforço comum, sob a segura liderança de Stalin.' (2005 : p. 118) 
Figura 8: Fotomontagem de John Heartfield para a Revista AIZ, n 27, 3/jun/1932

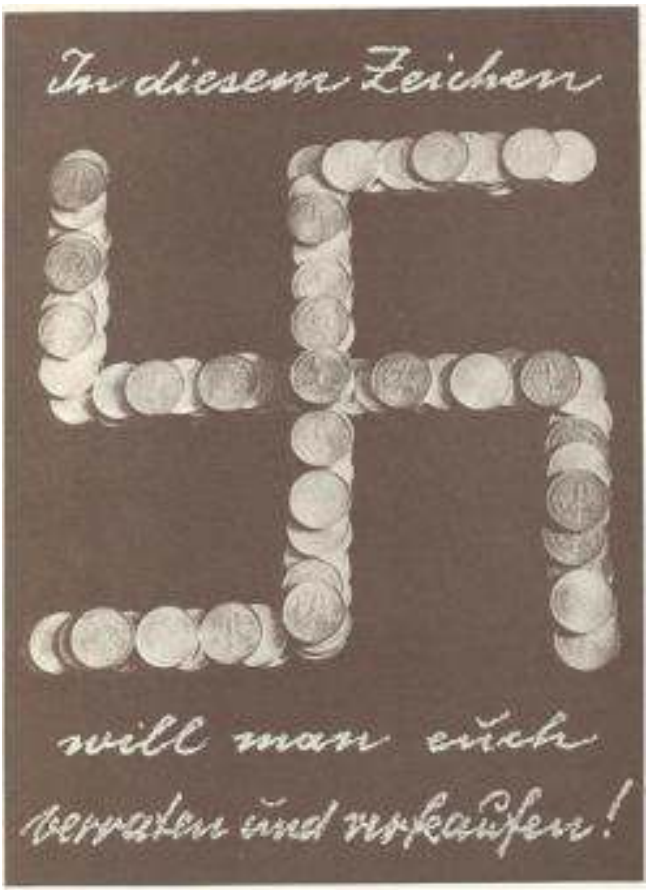

Na fotomontagem de Heartifield o texto diz "sob este sinal sereis traído e vendido"

Figura 9: Fotomontagem de Josep Renau para revista espanhola Orto, ago/1932

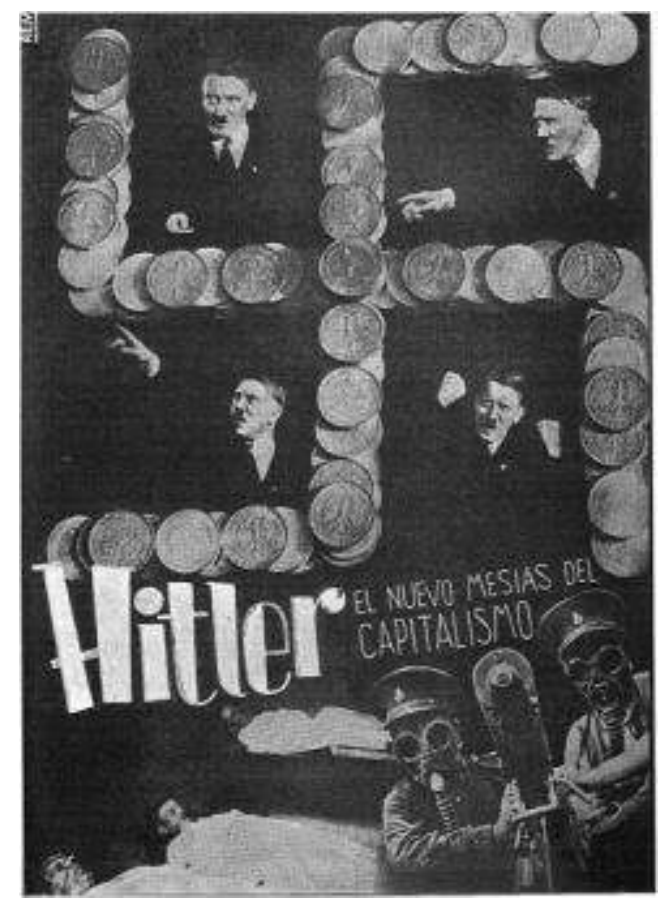

27 A fotomontagem do canto inferior esquerdo é de Josep Renau ${ }^{21}$ realizada a partir de outra de John Heartfield. Renau trabalhava em geral com imagens de terceiros, mesclava imagens de publicações internacionais com espanholas como fica evidente na fotomontagem "Hitler o novo messias do capitalismo" publicada pela primeira vez na 
revista espanhola Orto de agosto de 1932. (Figura 9) Nela ele se apropria de uma fotomontagem de John Heartfield publicada na AIZ de 3 de junho de 1932. (Figura 8).

A fotomontagem de Heartfield procura caracterizar com a suástica de moedas a relação existente entre o Partido Nazista com as altas finanças. Esta vinculação aparece em outras imagens de sua autoria da mesma época. Já a fotomontagem de Renau se apropria da de Heartfield, embora sem os textos da mesma e inclui quatro retratos de Hitler com os braços em diferentes posições possivelmente durante um discurso. Estes retratos de Hitler dão uma sensação de movimento o que denota uma aproximação com a linguagem cinematográfica. Lembremos que a própria concepção de montagem possui afinidades com as teorias cinematográficas de Serguei Eisentein (FABRIS, 2013: 12) No canto inferior direito três pessoas mortas envoltas em mortalhas; a que esta em primeiro plano parece ferida com sangue escorrendo do rosto, no canto inferior esquerdo soldados com máscaras de gás e uma metralhadora. É uma clara alusão ao momento de confronto e de embates vividos pela Espanha entre o bloco fascista e o bloco da esquerda. Nada mais apropriado como arma política e propagandística do que retomar a iconografia de combate de Heartfield denunciando a ascensão fascista alemã para atacar os grupos fascistas espanhóis.

Josep Renau foi um autor polifacético com produções em fotomontagem, cartazista, desenho gráfico, muralismo e cinema. Suas referências formativas como nos diz Joan Fontcuberta "começa com a art déco, para entroncar logo com o surrealismo e a vanguarda centro-européia ligada ao construtivismo". (FONTCUBERTA, 2001: 395) Ainda na questão estética antecipa-se a propostas da Pop Arte com um "realismo que busca sua inspiração na cultura de massas, a predileção por uma iconografia chamativa, uma ironia sobre os mitos consumistas e uma grande funcionalidade ótica". (FONTCUBERTA, 2001: 396)

30 As fotomontagens de Renau são beligerantes e populares, são mais densas e barrocas e se valem de metáforas diretas e grotescas - em contraposição à sobriedade de Heartfield. Ainda segundo Fontcuberta o tom grotesco ou burlesco pode advir da criatividade popular do folclore valenciano. (FONTCUBERT, 2001: 396) Plasticamente propiciava soluções visuais de jogos de contraposição figura/fundo, sacrificava a perspectiva ao significado e a naturalidade das cores ao efeito. Não se preocupava em dissimular os cortes e as junções entre os diferentes fragmentos. Outra diferença com relação a outros fotomontadores é que só trabalhava com material visual alheio.

Essa capa de Frente a Frente portanto através de suas apropriações realiza uma ponte entre o construtivismo russo, as vanguardas espanholas para falar da situação internacional para um publico mexicano. Bem distante das primeiras capas com estilo mais tradicional do realismo socialista. 
Figura 10: Capa da revista Frente a Frente com fotomontagem de Lola Alvarez Bravo

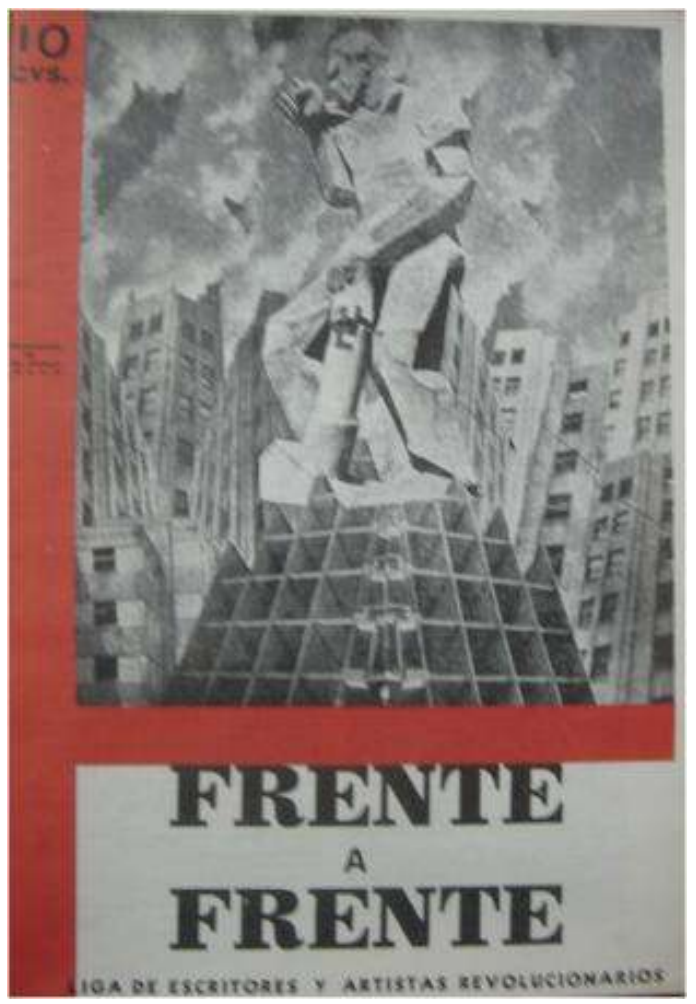

Poderíamos analisar outras imagens da revista, mas tomemos apenas mais um exemplo. É a capa do último número da revista com uma nova fotomontagem da fotógrafa mexicana Lola Álvarez Bravo ${ }^{22}$. Ela foi uma pioneira da fotomontagem no México. Talvez a obra mais conhecida dela seja 'O sonho dos pobres' (1935) em que aparece uma criança dormindo quase que atropelada por uma engrenagem feita de moedas.

Sua fatura (Figura 10) lembra imagens futuristas, em uma espécie de monumento operário ao estilo soviético e cubista de gesso que destrói com sua mão um míssil da agressão fascista. Em segundo plano arranhas céus modernos de aço e vidro de formas modernistas encimados por um céu de nuvens tormentosas. A imagem trás um claro geometrismo típico do vanguardismo construtivista russo. Lola com uma grande capacidade de composição utiliza de maneira inovadora perspectivas alargadas e as fileiras de arranha-céus como um eixo horizontal e em contradição com o monumento como eixo vertical que se articula à maneira cubista. A superposição entre edifícios e monumento criam linhas de força na imagem que as remete à produção do grupo de Leopoldo Méndez e do Taller de Gráfica Popular e do ambiente político mexicano dos anos trinta. Essa fotomontagem remete a outra obra dos anos cinqüenta 'Anarquía urbana de la ciudad de México'. A presença na imagem dos edifícios modernos é uma temática característica do modernismo mexicano, assim como imagens da vida urbana, mecânica e industrial em contraposição à temática rural pitoresca e pictorialista de anos anteriores.

\section{Tensões e ambiguidades}

34 A revista é muito rica de temas que poderíamos ter aprofundado, mas fogem aos limites e objetivos desse artigo. Destaco apenas alguns temas que poderiam ser trabalhados, 
para além da riqueza visual da revista: os debates nos textos publicados que versam sobre os acontecimentos históricos dos anos trinta, assim como tratam a comunicação de massa, o cinema, o rádio, a arquitetura, teatro, poesia, arte proletária, educação socialista entre tantos outros. Outro tema é a percepção de seus editores e colaboradores das questões internacionais, em especial da América Latina e do Brasil em particular ${ }^{23}$.

Como apresentamos a revista é permeada por contradições e ambigüidades. Inicia sua trajetória como um veículo crítico ao governo mexicano de então e próximo a um projeto estético-ideológico da cultura proletária e do realismo socialista. Com as transformações em seu grupo editor e também do ambiente político mexicano, mais precisamente o rompimento de Cárdenas e Calles em 1935, assim como a política de Frente Ampla adotada pelos comunistas, muda de posição política e estética. Passa a apoiar o governo Cárdenas e em seu projeto visual o periódico transita de um projeto gráfico calcado na gravura com poucas fotografias, para uma ampla utilização de fotografia ${ }^{24} \mathrm{e}$ fotomontagens. Essa mudança estética provavelmente só foi possível com uma maior capacidade financeira, algo que só deve ter sido possível pelo apoio do Estado embora não tenhamos encontrado nenhuma referência direta a isso. ${ }^{25}$

No que toca ao projeto visual, devemos julgar essa mudança ocorrida em sua trajetória como algo natural. Afinal como afirma Laura González para a fotografia vanguardista mexicana, mas que aqui nos apropriamos para pensar nosso periódico:

'Entender a la fotografía mexicana de esas décadas como una práctica discursiva compleja en la que intervienen múltiples factores de producción y difusión facilita comprender sus características especificas como vanguardia: la mudanza de sus autores entre estilos aparentemente contradictorios (como el pictorialismo y el constructivismo), y su tránsito por géneros artísticos distintos, como la fotografía, la gráfica, la pintura y el cine.' (2006:24)

Ainda me valendo das reflexões de González Flores (2006: 28), a revista, com todas as suas contradições, é uma publicação que revela as complexidades de sua época, pois sua edição, em que pese suas tensões e ambiguidades, possui um caráter colaborativo entre diversos artistas-intelectuais, além de expressões artísticas como a retórica estéticopolítica ligada ao conceito do muralismo, do cinema, da publicidade e dos meios de comunicação de massa realizada por artistas de destacada importância na época. A utilização da fotomontagem, sua vinculação com temáticas como o urbano foram características dessa vanguarda. A publicação se mostrou como um feixe de contradições e as transformações ao longo de sua trajetória acumulam camadas de sentido que procuramos averiguar. Enfim a revista Frente a Frente é uma excelente plataforma para se investigar a complexa cultura visual mexicana e é um vetor privilegiado para perceber a mediação entre arte, sociedade e política no México dos anos trinta.

ÁLVAREZ BRAVo Manuel, Fotopoesia, São Paulo, Instituto Moreira Salles, 2011.

ANTONIO RodrígueZ José, 'El fotomontaje en México: una actitud sociopolítica', in Los Pinceles de la historia: la arqueología del régimen 1910-1955, GONZÁLEZ MELlo Renato, México, Museo Nacional de Arte, 2003, p. 42-50.

AZUela A., 'El Machete and Frente a Frente: art committed to social justice in México', in Art Journal, vol. 52, n¹, spring, 1993, p. 82-87.

BELL Simon, "Sobre la difícil conjunción de los términos 'fotógrafos' y 'obrero' en Francia”, in El Movimiento de la Fotografía Obrera [1926-1939]. Ensayos y Documentos, 
Madrid, Museo Nacional Centro de Arte Reina Sofia/Ministerio de Cultura/TF Editores, 2011, p.364-372. 99-132. Gili, 2005. Socialista. DEROISE Olivier, Fuga mexicana: un recorrido por la fotografía en México. Barcelona: Gustavo Gili, 2005.

DICCIONARIO de la Lengua Española Real Academia Española. http://buscon.rae.es/drae/ Consulta on-line em 27 de agosto de 2013.

FABRIS Annateresa, 'Entre arte e propaganda: fotografia e fotomontagem na vanguarda soviética' in Anais do Museu Paulista, São Paulo, Nova Série, vol. 13, n 1, jan-jun, 2005, p.

FABRIS Annateresa, 'Por um realismo crítico. John Heartfield e a história da arte', in John Heartfield: fotomontagens. schWARTZ Jorge e MONZANI Marcelo (orgs.) São Paulo, Museu Lasar Segall, 2013, p. 9-13.

FONTCUBERTA J., “De pós-guerra al siglo XXI', in La Fotografía en España: de los orígenes al siglo XXI. Vol XLVII - SummaArtis - Historia General del Arte. SÁNCHEZ VIGIL, Juan Miguel (coord), Madrid, Espasa Calpe, 2001.

FRENTE A FRENTE 1934 - 1938. Edición Facsimilar, México, Centro de Estudios del Movimiento obrero y Socialista, 1994.

GONZÁLEZ FLORES Laura, “Tránsitos y mudanzas de la fotografía moderna en México” en A.A.V.V., Territorios de diálogo. Entre los realismos y lo surreal. España, México y Argentina, México, MUNAL/Instituto de Investigaciones Estéticas, 2006.

GONZÁLEZ FLORES Laura, Fotografía y pintura: dos medios diferentes?, Barcelona, Gustavo

HERNANDEZ PEREZ Amanda, (2003) 'Las masas y los símbolos en la obra de Luis Arenal' in Los Pinceles de la historia: la arqueología del régimen 1910-1955, GONZÁLEZ MELLo Renato, México, Museo Nacional de Arte, pp 89-90.

MARÍN MARÍN Álvaro,'José Mancisidor', verbete in Diccionario de la Revolución Mexicana, TORRES PARÉS, Javier y VILLEGAS MORENO, Gloria (coord.), México, UNAM, 2010.

NAPOLITANO Marcos, 'A relação entre arte e política: uma introdução teóricometodológico', in Temáticas, UNICAMP, Campinas, vol. 37-38, 2011, p. 25-56.

OLIVEIRA Ângela Meirelles de, Palavras como balas: imprensa e intelectuais antifascistas no Cone Sul (1933-1939), São Paulo, Universidade de São Paulo - FFLCH (Tese de Doutorado), 2013.

ORTO (1932-1934), Revista de documentación social, Valencia, Centro Francisco Tomas y Valiente, 2 vols. Edição fac-similar, 2001.

REYES PALMA Francisco, “La LEAR y su verista de frente cultural” in Frente a Frente 1934 1938. Edición 1994 Facsimilar. México: Centro de Estudios del Movimiento obrero y 


\section{NOTAS}

1. Que por sua vez era a continuação de outro grupo a Lucha Intelectual Proletária (LIP) que existiu apenas durante o ano de 1931.

2. Me utilizo para essa parte das informações fornecidas por Francisco Reyes Palma, (1994) e do artigo de Alicia Azuela (1993).

3. Essa bandeira foi adotada na VI Congresso da Internacional Comunista em 1928 e encontrou eco na América Latina a partir de 1929 com a Conferência dos Partidos Comunistas. Na revista surge o termo 'Frente Único' em um texto denominado 'Síntesis de los principios declarativos de la LEAR' no primeiro numero. (Frente a Frente, $n^{\circ} 1$, nov. 1934, p. 3).

4. Entendemos cultura proletária ou prolekult como um movimento que surge logo após a Revolução Russa e defendiam não apenas uma ruptura de ordem estética mas também de ordem moral e ética. Propunham uma produção descentralizada, localista e que privilegiasse a mobilização cultural na construção de uma 'nova cultura' que gerasse uma 'nova sociedade socialista'. O principio básico era que os processos e produtos culturais proviessem da classe trabalhadora sem interferência de intelectuais. Os processos organizacionais tinham grande importância e privilegiavam a criação de clubes locais que se federavam. Já o realismo socialista surge a partir de meados dos anos trinta em particular após o $1^{\circ}$ Congresso de Escritores Soviéticos em Moscou e embora não haja consenso em torno do termo quatro características são principais : registro da realidade cotidiana; transmissão de uma visão heróica; pensamento vinculado por imagens; utilitarismo estético. Tais posições serão potencializadas com o Jdanovismo com a 'combinação entre a centralização e a multiplicidades de órgãos de controle cultural ; criação de paradigmas de criação genéricos, temáticos e formais ; integração ideológica, estética e organizacional de todas as áreas de criação; controle do conjunto das práticas artísticas em torno do eixo "produção-difusão-recepção" e, finalmente, concentração da produção oficializada em poucos artistas, aliada à massificação de sua difusão.' (NAPOLITANO, 2011 : 52). O Jdanovismo se dá principalmente a partir de meados dos anos quarenta e anos cinquenta. Para um debate sobre esses conceitos veja o artigo já citado de Marcos Napolitano (2011).

5. Nessa primeira fase não é indicado um 'editor responsável', apenas de um Comitê Editor em que constavam os seguintes nomes : Rab-Kor, M. Nava, David Alfaro Siqueiros, Leopoldo Méndez, Juan de la Cabada e Luis Arenal. No segundo número sai M. Nava e além dos já citados aparecem os nomes de José Ma. Benítez, Salvador Aviña Vera. Para o terceiro número o Comite editor é formado por Enrique González Aparicio, Rab-Kor, L. Méndez, Juan de la Cabada e Luis Arenal.

6. Fernando Gamboa foi um artista-intelectual mexicano. Formou-se na Academia de Belas Artes trabalhou na Secretaria de Educação Pública (SEP) foi pintor atuou como museografo, promotor cultural e diplomático. Foi diretor do Museu Nacional de Belas Artes e um dos fundadores do Instituto Nacional de Belas Artes. Teve uma atuação destaca na concessão de asilo a diversos artistas e intelectuais espanhóis no México nos anos 1930.

7. Em uma espécie de manifesto no seu primeiro número afirma '1- La Liga de Escritores y Artistas Revolucionarios (LEAR) es una organización de Frente Unico al servicio de la clase trabajadora contra el actual régimen capitalista y sus funestas consecuencias de crisis y degeneración con sus secuelas de fachismo, Imperialismo y Guerra.' (Frente a Frente, $\mathrm{n}^{\circ} 1: 3$ )

8. Batizado em homenagem a Júlio Antonio Mella líder comunista cubano assassinado no México em 1929.

9. Vicente Lombardo Toledano (1894-1968) foi um escritor, professor, sindicalista e político mexicano. Exerceu diversos cargos públicos como professor e conferencista. Foi um dos fundadores e dirigentes da Confederación de Trabajadores de México (CTM) atou no Partido Laborista e 
Partido Popular (depois Popular Socialista) entre outros. Teve uma relação conflituosa com os comunistas sendo muitas vezes criticado por eles.

10. A frase original era arquiteto de almas e teria sido cunhada por Máximo Gorki durante o congresso de 1934 em Moscou para referir-se aos debates entre Romain Rolland e Andre Gide. 0 artigo era 'Exposición de pintura organizada por la LEAR. Divagaciones y pretextos' El Machete, México, 23 de mayo de 1936. Veja a discussão com mais profundidade em Reyes Palma (1994: 12-14)

11. Raimundo Mancisidor era irmão de José Mancisidor. Temos poucas informações sobre ele apenas que foi deputado em Veracruz. Foi escritor de contos e romances curtos. Também organizou uma antologia de textos de Fernando de Lizardi editadas pela SEP em 1945.

12. Leopoldo Méndez (1902-1969) foi um dos principais artista plástico mexicano usou como expressão artística principal a gravura embora tenha trabalhado com murais, cartazes, desenhos entre outras expressões visuais. Participou do grupo estridentista, e atuou além da LEAR e foi um dos fundadores do Taller de Gráfica Popular. Suas gravuras foram amplamente conhecidas em toda a América Latina inclusive no Brasil onde algumas delas foram estampadas na revista comunista Horizontes de Porto Alegre. Voltaremos a este personagem mais à frente.

13. José Mancisidor (1895-1956) foi um escritor de contos e romances e participou do estridentismo. Foi jornalista e roteirista para o cinema e tetro. Foi professor de história em Escolas Normais. Originário de Veracruz lutou na Revolução Mexicana e posteriormente atuou nesse estado durante a gestão de Adalberto Tejada e na presidência de Cárdenas trabalha como assessor na Secretaria de Educação Pública, entrou para a LEAR e como membro da Liga participa do Congresso Antifascista de Valencia em 1937 (Marín Marín 2010, p. 571-574).

14. Veja o que fala o item 4 da Sínteses dos principios da LEAR '4 - Definir la posición de artistas y escritores reaccionarios, francamente al servicio del clero y la clase exploradora, y denunciar y desenmascarar implacablemente a los que con careta colorada pretenden penetrar, o están ya, dentro de las filas proletarias para traicionarlas, fingiendo defenderlas, es de las tareas más urgentes e importantes.' (Frente a Frente, $\mathrm{n}^{\circ} 1: 3$ )

15. Identificamos diversos autores em especial Leopoldo Méndez, Everardo Ramirez, Carreño Prieto, José Clemente Orozco, David Alfaro Siqueiros, Arroyito, LAB, Gonzalo de la Paz Pérez (GPO), José Chávez Morado entre outros. Muitas outras gravuras não foram possíveis de identificar a autoria.

16. José Chávez Morado (1909 - 2002) foi um artista plástico mexicano nascido em Guanajuato, próximo ao PCM atuou no TGP, pintou murais e sob o pseudônimo de Chon publicou desenhos no periódico Combate de Narciso Bassols. Foram de sua autoria os relevos da coluna no Museu Nacional de Antropologia e História.

17. Seu trabalho também foi chamado de Fotopoesia segundo Antonio Rodrigues (apud González Flores, 2006: 26) termo que foi título de uma exposição e posterior catálogo publicado pelo Instituto Moreira Salles no Brasil (2011).

18. Revista ilustrada que circulou com o nome de 1945 no ano anterior e fez uso em grande escala de fotografia e fotomontagens, teve curta duração - somente um ano. Era dirigida por Federico Silva e Luis ArenaL, consistia em uma publicação mensal feita por pintores, escultores, gravuristas e fotógrafos e que na virada do ano circulou com o nome de 1946.

19. Confirmando sua força no inconsciente ótico mexicano, nos anos setenta o artista chicano Rupert García se apropriou da fotografia de Álvarez Bravo para a produção de uma obra artística em forma de cartaz (Debroise, 319).

20. Gustav Klutsis (1895-1938) foi um fotógrafo letão que atuou como professor de arte e escritor. Casado com Valentina Kulagina outra artista soviética foi preso e morto em 1938. A grafia do nome varia porem optamos pela opção utilizada por FABRIS (2005).

21. Originário de Valencia (1907), colabora em diversas revistas ilustradas espanholas como La Esfera, a anarcosindicalista Orto (1932-1934), a libertária Estudios (1929-1937) a comunista Octubre 
(1933) e na Nueva Cultura (1935-1937). No governo republicano espanhol de Largo Caballero em 1936 foi nomeado Diretor Geral de Belas Artes sendo responsável pela proteção do patrimônio cultural espanhol e coloca sua vida em risco para salvar as obras do Museu do Prado. Renau foi o grande responsável do Pavilhão Espanhol na Exposição Internacional de Artes e Técnicas (Paris, 1937) quando foi exposta pela primeira vez a obra símbolo da luta contra o fascismo Guernica de Pablo Picasso. Em 1938 vamos encontrá-lo como encarregado da propaganda visual do Comisariado General del Estado Mayor Central. Com a derrota republicana e a vitória franquista se exila no México.

22. Dolores Concepción Martínez Anda ou como é mais conhecida Lola Álvarez Bravo (1907-1993), foi casada com Manuel Álvarez Bravo até 1934, manteve o nome de casada após a separação, atuou como fotógrafa e fotojornalista numa época em que tal atividade era eminentemente masculina. Com uma obra 'extensa como multifacética, pero, debe insertarse en un corriente que se relaciona temática y estilísticamente tanto con el modernismo fotográfico como con la llamada 'escuela mexicana de pintura" (Debroise, 2005 : 323).

23. Artigos como 'Salvemos a Luis Carlos Prestes !!', Frente a Frente, $\mathrm{n}^{\circ} 5$, agosto de 1936, p. 16, AMADO, Jorge 'Los modernos novelistas brasileños' $\mathrm{n}^{\circ} 12$, marzo, 1937, p. 7 ; ou a seção 'Hispoamérica Mártir' e artigos sobre o Peru, Venezuela entre outros demonstram uma preocupação com o subcontinente e um intercambio entre os intelectuais da região.

24. $O$ estudo das fotografias é outro tema que poderia ser aprofundado. Identificamos a autoria de apenas um pequeno número de fotografias como é caso de 'Gutmann' (provavelmente Enrique Gutmann nascido na Lituania em 1906 como Henrich Gutmann, emigrou para o México em 1933 trabalhou na revista Frente a Frente e na revista Futuro morreu em 1950). Outros fotógrafos identificados foram Manuel Álvarez Bravo, Manuel Montes de Oca. Rodolfo M. Galván, Manuel E. Piña, Ernesto Briseño. Mas muitas fotografias não constam a autoria. Algumas devem vir de órgãos de difusão soviético e pelo menos uma foi identificada da United Press.

25. A única pista que encontramos foi um artigo sobre a comemoração de uma ano de administração operária do Talleres Gráficos Nacional (TGN) (Frente a Frente, nº 8, marzo de 1937, p. 27-28.) a partir de uma decisão do governo mexicano sob a presidente de Lázaro Cárdenas. Embora no texto não afirmar que a revista seja imprensa lá, o relato que membros da LEAR (Leopoldo Méndez, Fernando Gamboa, Alfredo Arce e Pablo O'Higgens) decoraram com murais a sede da gráfica permite supor que seja nessas instalações que rodava as edições da publicação. Estamos em busca de mais informações sobre esse tema e do possível apoio governamental.

\section{RESUMOS}

O objetivo desse artigo é refletir sobre a experiência visual da revista mexicana Frente a Frente (1934-1937) publicação da Liga de Escritores y Artistas Revolucionários - LEAR (1933-1938). Após apresentar a trajetória da revista procuramos investigar o projeto visual da publicação e a complexidade de uma revista engajada e a tensão entre propostas de cultura proletária, realismo socialista e vanguarda. Procuramos averiguar a circulação da vanguarda fotográfica entre Europa e México no período entre guerras. Interessa-nos em particular a experiência da utilização de fotografias e fotomontagens.

Cet article porte sur la Revue mexicaine « Frente a Frente », qui fut publiée de 1934 à 1937, par la LEAR, Liga de Escritores y Artistas Revolucionarios (1933-1938). L'analyse est centrée sur la 
conception visuelle et l'engagement d'un magazine dans toute la complexité de ses propositions, révélant les diverses tensions entre culture prolétarienne, réalisme socialiste et avant-gardisme. Nous nous sommes aussi intéressés à la circulation des photographies de l'avant-garde, entre l'Europe et le Mexique dans la période entre les deux guerres. Enfin, nous avons accordé une attention particulière à l'utilisation de photographies et de photomontages au sein de cette expérience éditoriale.

\section{ÍNDICE}

Mots-clés: photographie, avant-garde, Frente a Frente, art et politique

Palavras-chave: fotografia, vanguarda, Frente a Frente, arte e política

\section{AUTOR}

\section{CARLOS ALBERTO SAMPAIO BARBOSA}

UNESP/Assis Professor de História da América Latina casbeto[at]hotmail.com 